\title{
Validity and Reliability Assessment of Attitude Scales for Hepatitis B Vaccination Among Parents in Ho Chi Minh City, Vietnam
}

This article was published in the following Dove Press journal: Risk Management and Healthcare Policy

\author{
Giao Huynh (D) \\ Duong Uyen Binh Pham ${ }^{2}$ \\ Truong Vien Nguyen (ID) \\ Vinh Quang Bui $\mathbb{D}^{3}$ \\ Thi Ngoc Han Nguyen $\mathbb{D}^{4}$ \\ Dang Dung Nguyen' \\ Le An Pham $\mathbb{1 D}^{5}$
}

'Faculty of Public Health, University of Medicine and Pharmacy at Ho Chi Minh City, Ho Chi Minh City, Vietnam; ${ }^{2}$ Quality Assurance of Education, University of Medicine and Pharmacy at Ho Chi Minh City, Ho Chi Minh City, Vietnam;

${ }^{3}$ Department of Pediatrics, University of Medicine and Pharmacy at Ho Chi Minh City, Ho Chi Minh City, Vietnam; ${ }^{4}$ Infection Control Department,

University Medical Center Ho Chi Minh City, Ho Chi Minh City, Vietnam; ${ }^{5}$ Center for Training in Family Medicine, University of Medicine and Pharmacy at Ho Chi Minh City, Ho Chi Minh City, Vietnam
Correspondence: Giao Huynh; Duong Uyen Binh Pham

University of Medicine and Pharmacy at Ho Chi Minh City, 217 Hong Bang Street, District 5, Ho Chi Minh City, Vietnam Tel +84908608338; +849026609l6 Email hgiaoytcc@ump.edu.vn, p.d. uyenbinh@gmail.com
Background: Attitudes and beliefs could be associated with the low number of vaccinations in low- to middle-income countries such as Vietnam. This study aims to describe ways to develop and assess the attitudes towards Hepatitis B vaccination.

Methods: A mixed-method study was carried out between April 2015 and July 2017. Qualitative data were gathered via semi-structured interviews and focus group discussions. The data were then analyzed thematically into four domains of the Health Belief Model (HBM) in order to design the structured questionnaire. The quantitative strand was followed by the evaluation of the reliability and the construct validity, for which data were obtained after interviewing 768 parents whose children aged from 12 to 24 months, who were receiving the vaccines as part of the Expanded Programme on Immunization (EPI) schedules at the Commune Health Centers.

Results: The findings showed the content validity index value of 13 items ranged from 0.86 to 1.00 . The factor analyses showed that 11 items remained in the final questionnaire after deleting 2 problematic items due to no relation to the total scales and revealed four factors (perceived susceptibility, perceived severity, perceived benefits, perceived barriers) that jointly accounted for $62.1 \%$ of the observed variances. All four factors have good internal consistency with a total Cronbach's alpha of 0.735 . A confirmatory factor analysis demonstrated the proposed factor model which fits well in four domains of HBM.

Conclusion: Attitude scales for Hepatitis B vaccination based on HBM have been developed. This has confirmed to be a valid and reliable instrument that might be useful in assessing parents' attitudes regarding Hepatitis B vaccination and may be used to promote interventions within the increasing vaccination coverage for Vietnamese children.

Keywords: Hepatitis B, vaccination, children, reliability, Health Belief Model

\section{Background}

The World Health Organization (WHO) reported that approximately 257 million people around the world have chronic Hepatitis B (with Hepatitis B surface antigenpositive), and 887,000 deaths associated with cirrhosis and hepatocellular carcinoma occurred in 2015. ${ }^{1}$ Hepatitis B infection is considered one of the major health problems in Vietnam, with 8.4 million people having an HBV infection resulting in $23,300 \mathrm{HBV}-$ related deaths in $2005 .^{2}$ The high rate of HBsAg in children $(9.3 \%$ to $14.1 \%$ ), suggests that the main transmission channel is from mother to infant (MTCT). ${ }^{3}$ The risk of chronic Hepatitis B infection directly related to age, whereby $80-90 \%$ of children infected at birth will also become infected with chronic 
Hepatitis B, while the probability will be only $5 \%-10 \%$ if they are infected occurs after 5 -years of age. ${ }^{4}$ The vaccine is a key factor to HBV protection, with $98-100 \%$ protection from contracting Hepatitis $B$ when a child is vaccinated. ${ }^{1}$ Presently, the Hepatitis B vaccine is available and free of charge for Vietnamese children under 12 months of age on the Expanded Program on Immunization (EPI). However, the previous studies found that the percentage of Hepatitis $\mathrm{B}$ birth dose vaccinations were still low, at only $46.6 \%$ and $62.8 \%$. $^{5,6}$ Also, the birth dose coverage declined to $55 \%$ in 2013 and 2014 by the Adverse Events Following Immunization (AEFI). Several AEFIs occurred involving both the hepatitis B monovalent vaccine used for the birth dose and the pentavalent vaccine used for the 3-dose series in 2013. ${ }^{7}$ Nevertheless, the importance of the Hepatitis B birth dose vaccine, followed by three additional doses of the pentavalent vaccine (including Diphtheria, Pertussis, Tetanus, Hepatitis B, Hib) at 2, 3 and 4 months, is still important because it will protect from vertical (mother to child at birth) and horizontal transmission during early childhood. Little is known about Hepatitis B vaccination acceptance among parents, on which this study could guide future interventions. ${ }^{8}$ To explain the differences in Hepatitis $B$ vaccination behavior, such as unimmunized or delayed or timely immunized children, the Health Belief Model (HBM) is used as a social cognition model and includes factors that may support determining health-related behaviors and the probability of behavior change. According to HBM, in order to accept the vaccination, people must believe that: (i) they have a probability of contracting HBV (perceived susceptibility), (ii) HBV infection would have a negative influence on their lives (perceived severity), which is a concept of perceived threat including combination susceptibility and severity, (iii) The likelihood of a positive result from Hepatitis $B$ vaccination (perceived benefits), and (iv) barriers related to inconvenience of being vaccinated or side effects, in decisionmaking (perceived barriers). ${ }^{9}$ Previous studies have made standardized measures of HBM constructs but most of the target groups were high-risk groups (men having sex with men, and immigrant groups) and groups with specific illnesses (chronic Hepatitis B infection and HBV carriers), as highlighted in Ma GX's study with HBV vaccination behavior among Chinese and Vietnamese immigrants, and Rhodes S.D's study for men having sex with men, ${ }^{10,11}$ Bigham's study assessed the Hepatitis B immunization behavior of British Columbian mothers, however, this study used a questionnaire of the Immunization Health Belief Model scale with the target group being university students immunized and not immunized for measles, ${ }^{12}$ the Kim Y.O's study assessed attitude and HBV vaccination behavior of Korean immigrants that used the instrument in Bates et al which found factors related to pediatric health service use, ${ }^{13,14}$ Smith P.J. evaluated parental delay or refusal to vaccinate children aged 24 months of age, ${ }^{15}$ and recent research was performed by Hae Won Kim, assessing the HBM scales toward Human Papilloma Virus (HPV) vaccination. ${ }^{13}$ All have been shown that the HBM was a good fit in interpreting the vaccination behavior (All Cronbach's alpha >0.70). However, there were no reliable and valid instruments to measure the attitudes of parents towards the Hepatitis B vaccination, especially when the coverage of vaccination seriously declined by the Adverse Events Following Immunization. This study aims to develop an attitude measurement instrument for parents with reference to Hepatitis $\mathrm{B}$ vaccination in Ho Chi Minh City, based on HBM, in order to conduct interventions resulting in increasing vaccination coverage for children.

\section{Methods \\ Design and Context}

A total of 824 participants including 56 parents were included in the qualitative strand $(\mathrm{N}=56)$ and 768 in the quantitative strand $(\mathrm{N}=768)$, performed between April 2015 and July 2017 (Figure 1). A mixed-methods study was performed with the context being that the coverage of the Hepatitis B vaccine was low by AEFIs in 2013. There was a dramatic decline in the coverage of the birth dose HBV being administered to newborn babies (76\% to $56 \%$ ), followed by a decrease in the coverage of threedose vaccine (97\% to $59 \%$ ) in $2012-2013$, which led to a reduction in parents' belief in vaccination. ${ }^{16}$

\section{Qualitative Strand to Find the Insight Key Words for HBM in the Vietnamese Context}

A purposeful sampling strategy was carried out on 56 parents whose children were receiving vaccines in the EPI at two immunization centers in Ho Chi Minh City. The participants were invited to an interview or focus group discussion towards Hepatitis $\mathrm{B}$ vaccination. To understand insight into the context of parents' decisions to immunize, the semi-structured questionnaire was 

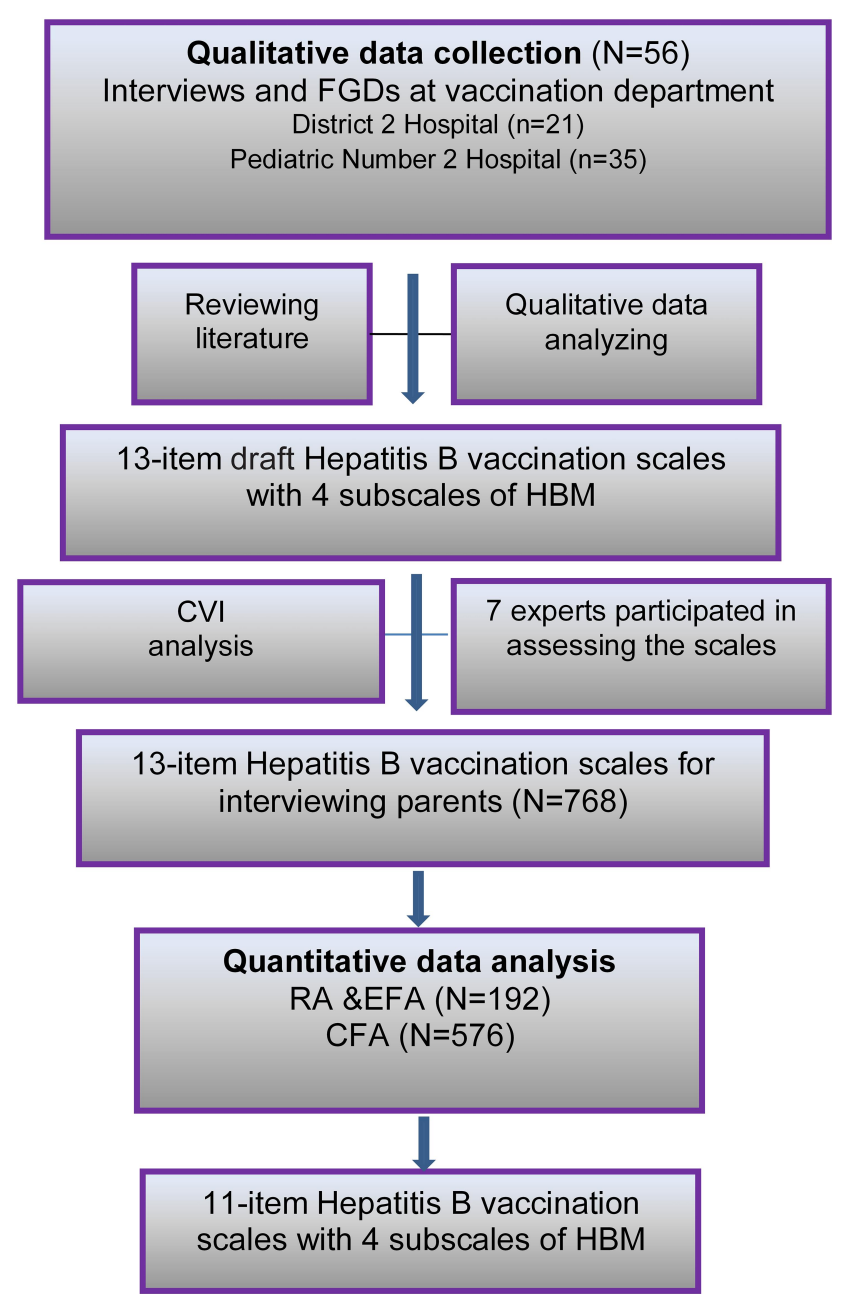

Figure I Mixed methods design: Qualitative $(N=56)$ and quantitative $(N=768)$ strands with data collection and analysis procedures.

Abbreviations: FGDs, Focus Group Discussions; HBM, Health Belief Model; CVI, Content Validity Index; RA, Reliability Analysis; EFA, Exploratory Factor Analysis; CFA, Confirmatory Factor Analysis.

classified based on four domains of the HBM concepts: (i) Perceived susceptibility to HBV infection including the item: Who can get HBV? (ii) Perceived severity of HBV infection including the item: How dangerous is HBV? (iii) Perceived benefits including the item: What do you know about the benefits of receiving the Hepatitis B vaccination? (iv) Barriers of vaccination including the items: Which factors make it difficult for you to obtain an HBV vaccination for your child? and, "What are the barriers influencing your decision to get your child vaccinated". Data that was collected from the transcripts were coded using Nvivo10, which was used to record our theme, and the extracted codes were used to design the instrument. After that, items of the scale were obtained by reviewing the literature on hepatitis B vaccination and investigating HBM scales. The resources of reviewing comprehensive data included
Pubmed and Google scholar. Some of the keywords used for the search were including Hepatitis B, validity, vaccination, HBM scales, reliability, and Health Belief Model. A process of the adaptation of HBM scales of Champion ${ }^{17,18}$ and the HBM scales toward immunization of Bigham ${ }^{12}$ were selected, primarily, for developing our scale. Then, analyses of the qualitative research regarding parents' perception about Hepatitis B disease and vaccine, and barriers causing a refusal or delay in $\mathrm{HBV}$ vaccination for their children were described in our previous study. ${ }^{19}$ The keyword findings in this qualitative strand assisted by contributing valuable content to our study's scale that matches HBM with the design and assessment of the questionnaire in the quantitative strand. The mixedmethods study was considered to ensure the validity and accuracy of our study results (Figure 1). Finally, 13-item draft scales with 4 subscales were created after combining the literature and the findings in the qualitative research obtained using the HBM scales. ${ }^{19,20}$

\section{Adaptation Procedures}

In the next stage, the 13-item draft scales were sent to seven experts specializing in multidisciplinary areas relevant to the study, who were the leaders of the fields such as infectious diseases ( 2 persons), epidemiologists ( 2 persons), and community medicine (3 persons). They were asked to rate the clarity and full content of the items using a four-point Likert scale ranged from 1 point (cannot be used, not relevant) to 4 points (very relevant). Additionally, the experts were also invited to suggest modifications to improve the content of items, if needed, which is to ensure the content validity of the questionnaire. According to the findings, no items were removed from the scale, most experts agreed with the subject "I" and removed the words "believed that" to form simple questions but still ensures the clarity of the questionnaire. However, some items needed to change such as the terms "risk" (item 1), and "need to get Hepatitis B vaccination" (item 7) should also include the words "high risk", and "need to get Hepatitis B vaccination on schedule", respectively, to ensure comprehension of the participants. Other items with some grammatical and spelling errors were corrected. After modifying words and sentences, the final version was achieved.

\section{Quantitative Strand}

A cross-sectional study was conducted with a simple random sample of 768 parents whose children were receiving 
the vaccination in the Vietnam EPI for children from 12-24 months at $16 \mathrm{CHCs}$ in Ho Chi Minh City, including delaying or refusing the Hepatitis B vaccine or timely immunized children. All were interviewed with a structured questionnaire that consisted of the demographic characteristics, and 13- item attitude scales focused on the Hepatitis B vaccination.

\section{Method of Analysis}

Data was analyzed by using STATA software 13.0. We used frequencies and percentages to describe the demographics of participants. According to the concurrence of experts, the content validity of items were confirmed using the content validity index for items (CVI). The CVI was calculated as the number of experts giving rating 3 or 4 to an item divided by the total number of experts. Because there were more than five experts in the expert panel, the CVI must have achieved 0.83 or more. $^{21}$ The 13 -item attitude scales included perceived susceptibility (2 items), perceived severity (3 items), perceived benefits ( 3 items), perceived barriers ( 5 items). Each item was evaluated on a 5-point Likert format ranged from 1 (strongly agree) to 5 (strongly disagree). Data of the 768 participants were divided randomly into two samples. For the first sample, split into a quarter sample $(\mathrm{N}=192)$, consistency reliability analysis (CRA), an exploratory factor analysis (EFA) was performed. Cronbach's alpha was determined for estimating the internal consistency of the scales, a value of Cronbach's alpha $\geq 0.7$ was considered

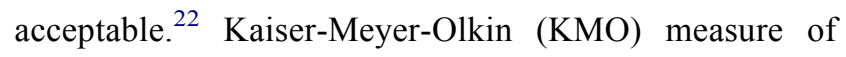
sampling adequation and Bartlett's test of sphericity were realized (the KMO measure value more than 0.7 and $\mathrm{p}<0.05$ is accepted). EFA extracted factors based on the Eigenvalues of more than 1 and used procedures of principal component extraction (PCA) and varimax rotation. A cut-off level for factor loading on each factor was defined at a value of 0.3 or more. ${ }^{23}$ The remaining split of the three-quarters sample $(\mathrm{N}=576)$ was used for CFA analysis to assess the sufficiency of a proposed factor structure. A single factor index is not considered as adequate to report the good fit between an assessed model and a theoretical model. ${ }^{11}$ The following indices were used for CFA to estimate the fit of the model: $\chi 2$ statistic, the root mean square error of approximation (RMSEA), the comparative fit index (CFI), TuckerLewis index (TLI), Standardized root mean squared residual (SRMR), Coefficient of Determination (CD).
A good fit of the model was considered sufficient when a value of CFI and TLI were greater than 0.90 , RMSEA and SRMR were from 0.06 to $0.08 .^{24,25}$

\section{Ethics Approval}

Our research complied with the Declaration of Helsinki. All the participants gave consent to engage in the study by signing the informed consent forms, as well as being aware they could withdraw from the study at any time without penalties. The study was approved by the Ethical Committee, University of Medicine and Pharmacy at Ho Chi Minh City, Vietnam (protocol number 125/UMPBOARD).

\section{Results \\ Qualitative Strand}

A total of 56 parents participated in an age range from 18 to 40 years old. Most reported secondary school as their highest level of education and the majority of them identified as housewives (an accepted term in Vietnam for homemakers with children).

\section{Experts Review About Content Validity}

The 13-item draft scales with 4 subscales of HBM was developed as an outcome of combining the findings in the qualitative strand and reviewing the literature. Following assessment by the experts' opinions were offered and CVI analysis was used. The CVI value of 13 items ranged from $0.86-1.00$, which was defined as good clarity and content.

\section{Participant Characteristics in Quantitative Strand}

Our results showed the similarities between sex, age, and education in RA and EFA, and the CFA sample. The test of significance did not show the difference between RA and EFA and CFA sample $(\mathrm{p}>0.05)$. Most participants were female $(81 \%)$ and had a mean age of $30.8 \pm 5.1$ years. About $85 \%$ of them reached secondary education level (Table 1).

\section{Consistency Reliability Analysis}

The 13-item draft scales were used to interview the 768 participants. After performing the internal consistency reliability analysis, two items were removed from the scales due to no relation to the total scales (item-test correlation $<0.3$ ). The remaining 11-item scales were shown in Appendix 1, 
Table I Sex, Age, and Education of Participants ( $N=768)$

\begin{tabular}{|c|c|c|c|c|}
\hline & $\begin{array}{l}\text { Total } \\
(\mathrm{N}=768)\end{array}$ & $\begin{array}{l}\text { RA and EFA } \\
(n=192)\end{array}$ & $\begin{array}{l}\text { CFA } \\
(n=576)\end{array}$ & $\mathbf{p}$ \\
\hline \multicolumn{5}{|l|}{ Sex } \\
\hline Male & $146(19.0)$ & $43(22.4)$ & $103(17.9)$ & $0.17 I^{*}$ \\
\hline Female & $621(81.0)$ & $149(77.6)$ & $472(82.1)$ & \\
\hline \multicolumn{5}{|l|}{ Education } \\
\hline Pre-primary education & $20(2.6)$ & $3(1.6)$ & $17(3.0)$ & Reference \\
\hline Primary education & $96(12.5)$ & $30(16.6)$ & $66(11.5)$ & $0.154^{\#}$ \\
\hline Secondary education & $592(77.2)$ & $|4|(73.4)$ & $45 I(78.4)$ & $0.367^{\#}$ \\
\hline Post-secondary education & $59(7.7)$ & $18(9.4)$ & $4 \mid(7.1)$ & $0.185^{\#}$ \\
\hline Age (Mean \pm SD) & $30.8 \pm 5.1$ & $30.5 \pm 4.7$ & $30.9 \pm 5.2$ & $0.370^{\#}$ \\
\hline
\end{tabular}

Notes: *Chi-square test; ${ }^{*}$ Logistic regression.

Table 2 Internal Consistency Reliability of the Attitude Scales Towards Hepatitis B Vaccination (N=192)

\begin{tabular}{|c|c|c|c|c|c|c|c|}
\hline \multirow[t]{2}{*}{ Item } & \multirow[t]{2}{*}{ Sign } & \multicolumn{3}{|c|}{ Original Scale } & \multicolumn{3}{|c|}{ Modified Scale } \\
\hline & & $\begin{array}{l}\text { Item- } \\
\text { Test } \\
\text { Corr. }\end{array}$ & $\begin{array}{l}\text { Item- } \\
\text { Rest } \\
\text { Corr. }\end{array}$ & Alpha & $\begin{array}{l}\text { Item- } \\
\text { Test } \\
\text { Corr. }\end{array}$ & $\begin{array}{l}\text { Item- } \\
\text { Rest } \\
\text { Corr. }\end{array}$ & Alpha \\
\hline I. My child is at high risk for Hepatitis B & + & 0.508 & 0.330 & 0.693 & 0.553 & 0.367 & 0.721 \\
\hline 2. I think my child will get Hepatitis B in future & + & 0.621 & 0.498 & 0.667 & 0.656 & 0.529 & 0.694 \\
\hline 3. My child could be very sick if she/he got HBV & + & 0.603 & 0.499 & 0.671 & 0.610 & 0.497 & 0.702 \\
\hline $\begin{array}{l}\text { 4. I am afraid to even think about my child getting sick with } \\
\text { HBV }\end{array}$ & + & 0.531 & 0.403 & 0.682 & 0.543 & 0.405 & 0.713 \\
\hline 5. Immunization will prevent my child from catching HBV & + & 0.603 & 0.519 & 0.674 & 0.631 & 0.544 & $0.70 \mathrm{I}$ \\
\hline $\begin{array}{l}\text { 6. By being immunized and not getting HBV, my child will be } \\
\text { protecting others from HBV }\end{array}$ & + & 0.475 & 0.324 & 0.692 & 0.475 & 0.311 & 0.727 \\
\hline $\begin{array}{l}\text { 7. Need to get the Hepatitis } B \text { vaccination on schedule to } \\
\text { prevent my child from getting HBV }\end{array}$ & + & 0.491 & 0.376 & 0.686 & 0.519 & 0.398 & 0.715 \\
\hline 8. The Hepatitis $B$ vaccine can cause AEFIs & - & 0.436 & 0.287 & 0.697 & 0.455 & 0.294 & 0.728 \\
\hline 9. The Hepatitis B shot can be painful & - & 0.383 & 0.190 & 0.715 & 0.381 & 0.172 & 0.754 \\
\hline 10. It is an inconvenient time to take my child in for vaccines & - & 0.537 & 0.433 & 0.681 & 0.523 & 0.408 & 0.714 \\
\hline $\begin{array}{l}\text { II. That is an inconvenient location to take my child in for } \\
\text { vaccines }\end{array}$ & - & 0.573 & 0.476 & 0.677 & 0.578 & 0.473 & 0.707 \\
\hline 12. Hepatitis $B$ is a dangerous disease & + & 0.289 & 0.167 & 0.709 & Excluded & & \\
\hline 13. Watching my child get needles frightens me & + & 0.288 & 0.082 & 0.733 & Excluded & & \\
\hline Total & & & & 0.708 & 0.735 & & \\
\hline
\end{tabular}

which demonstrated acceptable internal consistency with Cronbach's alpha of 0.735 . The correlation of each item to the scales ranged from moderate to strong (item-test correlation from 0.381 to 0.656 ) (Table 2).

\section{Factor Analysis}

In the factor of the post-estimation of the HBM scales, KMO measure value was 0.738 , and $p<0.001$ of Bartlett's test of sphericity demonstrated satisfactory suitability of 
Table 3 Exploratory Factor Analysis for Attitude Scales Towards Hepatitis B Vaccination (N=192)

\begin{tabular}{|c|c|c|c|c|}
\hline \multirow[t]{2}{*}{ Item } & \multicolumn{4}{|c|}{ Factors } \\
\hline & $\mathbf{I}$ & 2 & 3 & 4 \\
\hline I. My child is at high risk for Hepatitis B & 0.880 & -0.091 & 0.064 & -0.106 \\
\hline 2. I think my child will get Hepatitis B in future & 0.573 & 0.282 & 0.035 & -0.063 \\
\hline 3. My child could be very sick if she/he got HBV & 0.653 & 0.130 & 0.117 & 0.121 \\
\hline 4. I am afraid to even think about my child getting sick with HBV & 0.683 & -0.211 & -0.176 & 0.083 \\
\hline 5. Immunization will prevent my child from catching HBV & 0.182 & 0.332 & -0.095 & 0.266 \\
\hline 6. By being immunized and not getting HBV, my child will be protecting others from HBV & -0.037 & 0.890 & 0.082 & -0.148 \\
\hline 7. Need to get the Hepatitis B vaccination on schedule to prevent my child from getting HBV & -0.113 & 0.605 & -0.023 & 0.282 \\
\hline 8. The Hepatitis B vaccine can cause AEFIs & -0.046 & -0.288 & 0.626 & 0.164 \\
\hline 9. The Hepatitis B shot can be painful & 0.078 & 0.158 & 0.874 & -0.069 \\
\hline 10. It is an inconvenient time to take my child in for vaccines & -0.063 & -0.050 & 0.038 & 0.927 \\
\hline 11. That is an inconvenient location to take my child in for vaccines & 0.021 & -0.064 & -0.029 & 0.886 \\
\hline Eigenvalue & 3.34 & 1.42 & 1.05 & 1.01 \\
\hline Explained variance & $30.4 \%$ & $13.0 \%$ & $9.5 \%$ & $9.2 \%$ \\
\hline Cumulative of explained variance & $62.1 \%$ & & & \\
\hline
\end{tabular}

the data to factor analysis, which showed that our variables are associated to and appropriate for structure detection.

\section{Exploratory Factor Analysis}

A loading cut-off level of 0.3 or more was used with the findings resulting in 11 items being approved, numbered from 1 to 11 , and 2 items were deleted. Most of the items had factor loadings ranging from 0.573 to 0.927 , with item 5 being a moderate loading on the perceived benefits factor (0.332). Following the Scree plot made by the method of principle-component factor, the number of the consisted factor was reported as four. The EFA found four factors of HBM scales were extracted including the perceived threat of disease, which was determined by a combination of perceived susceptibility and perceived severity (item 1 to 4 ), perceived benefits (item 5 to 7), while the barriers were divided into 2 subscales covering barriers of side effects (item 8 and 9), and inconvenience of being vaccinated (item 10 and 11). The factor analyses revealed four factors (perceived susceptibility, perceived severity, perceived benefits, perceived barriers) containing 11 items that jointly accounted for $62.1 \%$ of the observed variance (Table 3).

\section{Construct and Concurrent Validity}

Figure 2 revealed the standardized solution for the fourfactor measurement model, that observed variables were described by rectangles, and latent variables were enclosed in ellipses, 4-items served as indicators of perceived threat, 3 -items served as indices of perceived benefits, 2- items of perceived barriers of side effects and 2-items of the inconvenience of being vaccinated. The CFA revealed a model of the strong correlation of each factor with another with standardized covariances ranging from 0.32 to 0.63 . Factor loadings of 9 items were good (ranging from 0.50 to 0.92 ), and of two remaining factors were acceptable $(0.32$ and 0.34). Multiple-squared correlation coefficients ranged from 0.15 to 0.90 . These results indicated an acceptable to good ability to explain factors relating to the variation of items in the model (Figure 2). Fit statistics for the CFA model showed an unfit 4-factor model using LR test (Likelihood Ratio test) for model or baseline versus saturated comparison, corresponding to $X^{2}(38)=114.33$, $\mathrm{p}<0.001, X^{2}(55)=1025.4, \mathrm{p}<0.001$, which indicated the expected model and the observed model are significantly different. This can be explained by the large sample size that can affect these statistics leading to rejects in the model. However, all of other fit statistics revealed a good 


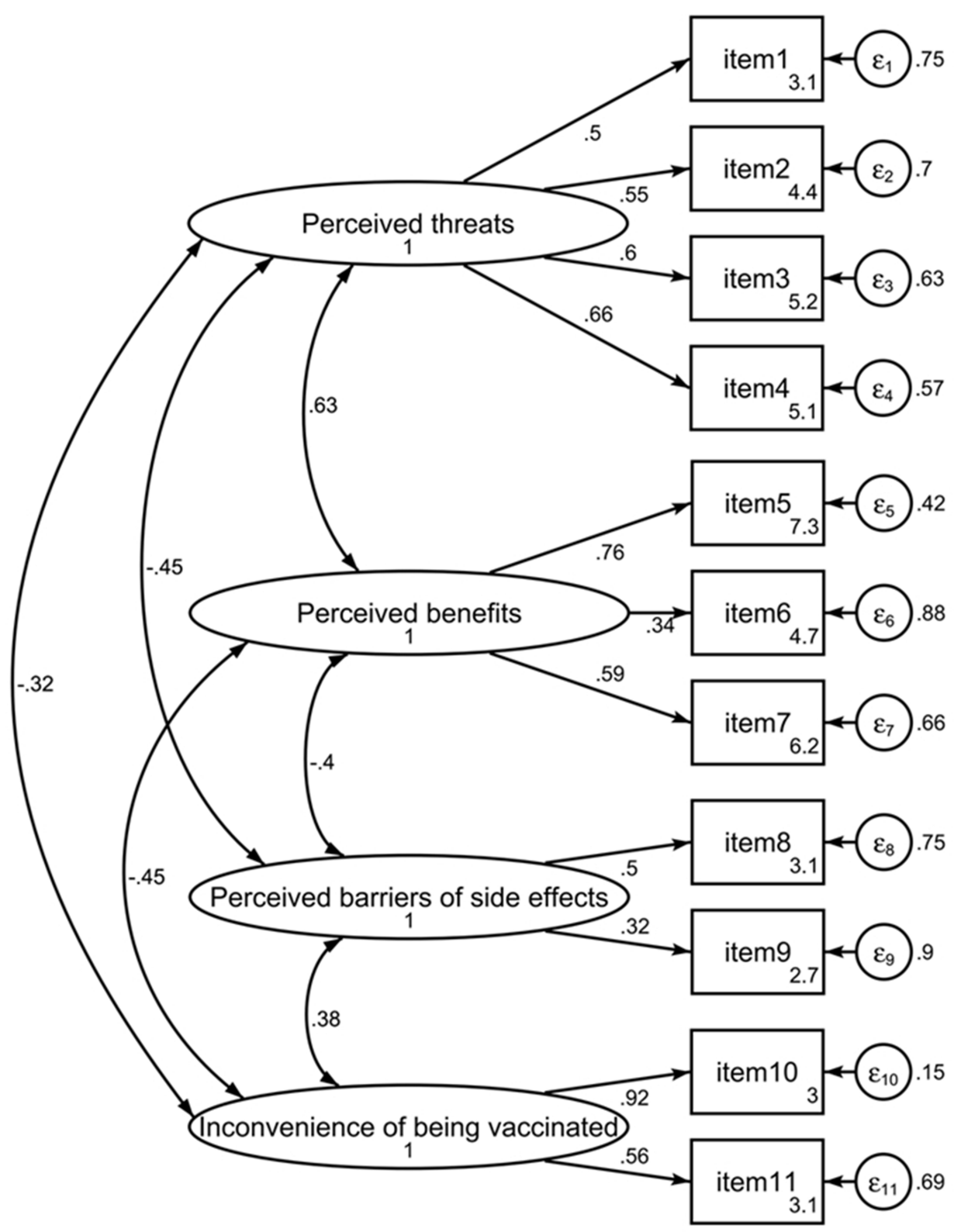

Figure 2 Confirm factor analysis for Attitude Scales towards Hepatitis B Vaccination ( $N=576)$.

Notes: Oval, Endogenous variable; Value in oval, Standardized variance; Rectangle, Exogenous variables; Value in rectangle, intercept; $\varepsilon$, random errors; Value on one-way arrows are standardized factor loading; Value on two-way arrows show Covariances.

fit of the model specified such as CFI (0.921), TLI (0.886), SRMR (0.039), CD (0.984), RMSEA $(0.059,90 \%$ CI = 0.04-0.072) (Table 4). Overall, the data showed that the scales had adequate factorial validity.

\section{Discussion}

Developing interventions to achieve behavioral change is the main goal to increase the coverage of $\mathrm{HBV}$ vaccination, especially following AEFIs in 2013, which significantly reduced parents' belief in vaccination and increased the rate of vaccine refusal and delays in take up. Also, there was no reliable and valid instrument to assess patients' attitudes towards Hepatitis B vaccination. The HBM showed vaccination behavior is affected by perceived sensibility, the severity of the disease, perceived benefits, and barriers to vaccination, ${ }^{26}$ which were demonstrated by previous studies of Bigham ${ }^{12}$ and Rhodes ${ }^{11}$ about attitudes and beliefs toward Hepatitis B vaccination. However, it is necessary to have a suitable instrument for assessing the attitudes of parents toward their children's vaccination that will allow planned interventions to be more 
Table 4 Fit Statistic for CFA Model ( $N=576)$

\begin{tabular}{|c|c|c|}
\hline Fit Statistic & Value & $\begin{array}{l}\text { Expected } \\
\text { Value }\end{array}$ \\
\hline $\begin{array}{l}\text { Likelihood ratio test for model vs } \\
\text { saturated comparison } \\
X_{(38)}^{2} \\
\text { P-value }\end{array}$ & $\begin{array}{l}I 14.33 \\
<0.00 I\end{array}$ & $>0.05$ \\
\hline $\begin{array}{l}\text { Likelihood ratio test for baseline vs } \\
\text { saturated comparison } \\
X_{(55)}^{2} \\
\mathrm{P} \text {-value }\end{array}$ & $\begin{array}{l}I 025.40 \\
<0.001\end{array}$ & $>0.05$ \\
\hline $\begin{array}{l}\text { Population error } \\
\text { Root mean square error of } \\
\text { approximation (RMSEA) } \\
\text { RMSEA } 90 \% \mathrm{Cl} \text {, lower bound } \\
\text { RMSEA } 90 \% \mathrm{Cl} \text {, upper bound } \\
\text { pclose }\end{array}$ & $\begin{array}{l}0.059 \\
0.047 \\
0.072 \\
0.109\end{array}$ & $\begin{array}{l}<0.08 \\
<0.08\end{array}$ \\
\hline $\begin{array}{l}\text { Baseline comparison } \\
\text { Comparative fit index (CFI) } \\
\text { Tucker-Lewis index (TLI) }\end{array}$ & $\begin{array}{l}0.921 \\
0.886\end{array}$ & $\begin{array}{l}>0.9 \\
\text { Close to I }\end{array}$ \\
\hline $\begin{array}{l}\text { Size of residuals } \\
\text { Standardized root mean squared residual } \\
\text { (SRMR) } \\
\text { Coefficient of determination (CD) }\end{array}$ & $\begin{array}{l}0.039 \\
0.984\end{array}$ & $\begin{array}{l}<0.08 \\
\text { Close to I }\end{array}$ \\
\hline
\end{tabular}

effective. In our study, using the mixed methods study including qualitative and quantitative strands on a sample of parents whose children receiving the vaccination at $\mathrm{CHCs}$ based on items of the HBM scales, showed the instrument was suitably developed for this subject. Additionally, the final scales were also modified according to the opinions of experts. Therefore, it would ensure the comprehensiveness of the results. The content of all items was validated by experts and adapted after minor changes, such as editing of words with corresponding synonyms. The 13 -item attitude scales for HBV vaccination in our study were structured into four factors as the theoretical framework of HBM. ${ }^{26}$ Most items achieved the agreement of experts, which resulted in good content validity, followed by the results construct validity, which was provided through exploratory factor analysis. The primary scales initially consisted of 13-items, however, two items, which are "HBV is a serious disease ", and "The Hepatitis B shot can be painful", were deleted from the scales because they were seen as having no relation to the total scale (item-test correlation $<0.3$ ). This was based on the recommendation that the researchers should remove the items with a factor loading under $0.32 .{ }^{23}$ The final scales of 11 -items showed good internal consistency with Cronbach's alpha of more than 0.7 , its value was similar to Rhodes's study about HBV vaccination ${ }^{11}$ and scale of Champion, ${ }^{17}$ but higher-level than that of Pielak KL's study about the HBM scale of measles immunization, ${ }^{27}$ and HBM scale for HPV vaccination of Kim $(0.71-0.78) .{ }^{13}$ The CFA supplied for the construct validity of HBM scales which consisted of a perceived threat; perceived benefits to vaccination; barriers related to side effects and inconvenience of being vaccinated, also CFA showed four stable subscales with comparative model fits, all the observed variables except for item 5 were strong measures of their latent factors, with factor loadings ranging from 0.573 to 0.890 . These findings showed to be higher than those reported on the scale of Champion, which had factor loadings ranging from 0.40 to $0.83 .{ }^{17,18}$ The scales revealed a good fit for a four-factor model using CFI, TLI, SRMR, CD, and RMSEA, although LR showed to be unfit. This might be because the $X^{2}$ was impacted by the sample size. ${ }^{28}$ These results were similar to Sun's study ${ }^{29}$ where the 5-factor model was not satisfactory for the $X^{2}$ test but had good fit indices, including CFI, TLI, and SRMR, RMSEA, CD. Overall, it is interpreted that the HBM scales of Hepatitis $B$ vaccination may be considered to have sufficient factor validity. Most of the psychometric tests of the scales were found to have satisfactory results.

\section{Strengths and Limitations}

This was a new study to assess the immunization scales based on the HBM. This contribution is good for future studies in the context that Vietnam was an endemic area for Hepatitis B and the rate of taking up of the hepatitis birth dose was low. Some limitations included that information was collected from parents whose children were aged from 12 to 24 months old, which can result in recall bias, and the sample was collected in a large city, which might not reflect attitudes and trends across all of Vietnam, especially the regional areas.

\section{Conclusions}

Attitude Scales for Hepatitis B Vaccination is a valid and reliable instrument that might be useful in assessing parents' attitudes regarding vaccination and assist in identifying ways to conduct interventions promoting ways of increasing vaccination coverage for children.

\section{Data Sharing Statement}

Available upon request to the first author. 


\section{Acknowledgments}

We thank Assoc. Prof. Phuc M. Vu, Assoc. Prof. Tuan A. Nguyen, Prof. Ninh H. Le, Assoc. Prof. Hoa TL. Pham, Assoc. Prof. Nga N. Cao, Dr. Chau VV Nguyen, and Assoc. Prof. Hung T Nguyen for participating as content expert reviewers. We thank Raymond A Kuschert for assisting in translation. We thank the parents for participating and nurses of Commune Health Centers for assisting in data collection.

\section{Author Contributions}

All authors made substantial contributions to conception and design, acquisition of data, analysis, and interpretation of data, took part in revising the article critically for important intellectual content, gave final approval of the version to be published, and agree to be accountable for all aspects of the work.

\section{Funding}

There is no funding to report.

\section{Disclosure}

The authors declare that they have no competing interests.

\section{References}

1. WHO. Global hepatitis report, 2017. 2017. Available from: https:// www.who.int/publications-detail/global-hepatitis-report-2017. Accessed September 20, 2020.

2. Nguyen VTT, Law MG, Dore GJ. An enormous hepatitis B virus-related liver disease burden projected in Vietnam by 2025 Liver Int. 2008;28:525-531. doi:10.1111/j.1478-3231.2007.01646.x

3. Nguyen VTT, Pham KN. Prevalence of HBsAg and HBeAg and risk factors for in school children in two communes of $\mathrm{Vu}$ Thu district, Thai Binh province, Vietnam. J Prac Med. 2002;433:34-38.

4. WHO. Hepatitis B. 2020. Available from: https://www.who.int/newsroom/fact-sheets/detail/hepatitis-b. Accessed September 20, 2020.

5. Pham TT, Le HM, Nguyen DT, et al. Assessment of the timely administration of the Hepatitis B and BCG birth dose and the primary infant vaccination schedule in 2015-2016 in the Mekong Delta, Viet nam. Vaccine. 2018;36(38):5760-5765. doi:10.1016/j.vaccine.2018.08.002

6. Nguyen Si Anh H, Vo HL, Hoang Bao L, et al. Hepatitis B birth dose vaccination among vietnamese children: implications for the expanded program on immunization. Biomed Res Int. 2019;2019:3453105. doi:10.1155/2019/3453105

7. United Nations International Children's Fund (UNICEF). Viet Nam: WHO and UNICEF estimates of immunization coverage: 2016 revision. 2016. Available from: https://data.unicef.org/wp-content /uploads/country_profiles/Viet\%20Nam/immunization_country_pro files/immunization_vnm.pdf. Accessed September 20, 2020.

8. WHO. Hepatitis B vaccines-WHO position paper-July 2017. Wkly Epidemiol Rec. 2017;92(27):369-392.

9. Janz NK, Becker MH. The health belief model: a decade later. Health Educ Q. 1984;11(1):1-47. doi:10.1177/109019818401100101

10. Ma GX, Shive SS, Toubbeh J, Wu D, Wang P. Risk perceptions, barriers, and self-efficacy of Hepatitis B screening and vaccination among Chinese immigrants. Int Electron $J$ Health Educ. 2006;9:141-153.
11. Rhodes SD, Hergenrather KC. Attitudes and beliefs about hepatitis $B$ vaccination among gay men: the birmingham measurement study. J Homosex. 2008;55(1):124-149. doi:10.1080/00918360802129386

12. Bigham M, Remple VP, Pielak K, McIntyre C, White R, Wu W. Uptake and behavioural and attitudinal determinants of immunization in an expanded routine infant hepatitis B vaccination program in British Columbia. Can J Public Health. 2006;97(2):90-95. doi:10.1007/BF03405322

13. Kim HW. Knowledge about human papillomavirus (HPV), and health beliefs and intention to recommend HPV vaccination for girls and boys among Korean health teachers. Vaccine. 2012;30 (36):5327-5334. doi:10.1016/j.vaccine.2012.06.040

14. Bates AS, Fitzgerald JF, Wolinsky FD. Reliability and validity of an instrument to measure maternal health beliefs. Med Care. 1994;32 (2):832-846. doi:10.1097/00005650-199408000-00006

15. Smith PJ, Kennedy AM, Wooten K, Gust DA, Pickering LK. Association between health care providers' influence on parents who have concerns about vaccine safety and vaccination coverage. Pediatrics. 2006;118(5):e1287-92. doi:10.1542/peds.2006-0923

16. WHO. WHO-UNICEF estimates of HepB3 coverage. 2015. Available from: https://apps.who.int/immunization_monitoring/global summary/timeseries/tswucoveragehepb3.html. Accessed September 20,2020

17. Champion VL. Revised susceptibility, benefits, and barriers scale for mammography screening. Res Nurs Health. 1999;22(4):341-348. doi:10.1002/(SICI)1098-240X(199908)22:4<341::AID-NUR8>3.0. $\mathrm{CO} ; 2-\mathrm{P}$

18. Champion V, Skinner CS, Menon U. Development of a self-efficacy scale for mammography. Res Nurs Health. 2005;28:329-336. doi:10.1002/nur.20088

19. Huynh G, Pham LA, Bui QV, Tran TT, Nguyen QV, Pauline EJ. Mothers' misconception about Hepatitis B disease and Hepatitis B vaccine. Int J Trop Dis Health. 2018;4(4):1-10.

20. Giao $\mathrm{H}$, Vinh $B Q, A n$ PL. Nhận thức sai lầm của bà mẹ về bệnh viêm gan $\mathrm{B}$ và vắc-xin viêm gan $\mathrm{B}$. T? $p$ Chi $Y$ H? c TPHCM. 2016;33:183-188.

21. Lynn MR. Determination and quantification of content validity. Nurs Res. 1986;35(6):382-385. doi:10.1097/00006199-198611000-00017

22. Tavakol M, Dennick R. Making sense of Cronbach's alpha. Int J Med Educ. 2011;2:53-55. doi:10.5116/ijme.4dfb.8dfd

23. Joseph FH, William CB, Barry JB, Rolph EA. Multivariate Data Analysis: Pearson New International Edition. 7th ed. London: Pearson Education Limited; 2014:151-230.

24. Bentler PM, Bonett DG. Significance tests and goodness of fit in the analysis of covariance structures. Psychol Bull. 1980;88(3):588-606. doi:10.1037/0033-2909.88.3.588

25. Hu LT, Bentler PM. Cutoff criteria for fit indexes in covariance structure analysis: conventional criteria versus new alternatives. Struct Eq Model. 1999;6:1-55. doi:10.1080/10705519909540118

26. Maiman LA, Becker MH, Kirscht JP, Haefner DP, Drachman RH. Scales for measuring health belief model dimensions: a test of predictive value, internal consistency, and relationships among beliefs. Health Educ Behav. 1977;5:215.

27. Pielak KL, Hilton A. University students immunized and not immunized for measles: a comparison of beliefs, attitudes, and perceived barriers and benefits. Can J Public Health. 2003;94(3):193-196. doi:10.1007/BF03405065

28. Lance CE, Butts MM, Michels LC. The sources of four commonly reported cutoff criteria. Organ Res Methods. 2006;9:202-220. doi:10.1177/1094428105284919

29. Sun J, Dunne MP, Hou X-Y, Xu A-Q. Educational stress scale for adolescents: development, validity, and reliability with Chinese students. J Psychoeduc Assess. 2011;29:534-546. doi:10.1177/ 0734282910394976 


\section{Publish your work in this journal}

Risk Management and Healthcare Policy is an international, peerreviewed, open access journal focusing on all aspects of public health, policy, and preventative measures to promote good health and improve morbidity and mortality in the population. The journal welcomes submitted papers covering original research, basic science, clinical \& epidemiological studies, reviews and evaluations, guidelines, expert opinion and commentary, case reports and extended reports. The manuscript management system is completely online and includes a very quick and fair peer-review system, which is all easy to use. Visit http://www.dovepress.com/testimonials.php to read real quotes from published authors. 